\title{
AIDS-Related Plasmablastic Lymphoma of Mucosa Site
}

National Cancer Institute

\section{Source}

National Cancer Institute. AIDS-Related Plasmablastic Lymphoma of Mucosa Site. NCI Thesaurus. Code C38160.

A plasmablastic mucosal site lymphoma in a patient with acquired immunodeficiency syndrome. 